\title{
Canopy Wetness and Humidity Prediction Using Satellite and Synoptic-Scale Meteorological Observations
}

\author{
M. C. Anderson, W. L. Bland, J. M. Norman, Department of Soil Science, University of Wisconsin-Madison, \\ Madison, WI 53706; and G. D. Diak, Cooperative Institute for Meteorological Satellite Studies, University of Wis- \\ consin-Madison, WI 53706
}

\begin{abstract}
Anderson, M. C., Bland, W. L., Norman, J. M., and Diak, G. D. 2001. Canopy wetness and humidity prediction using satellite and synoptic-scale meteorological observations. Plant Dis. 85:1018-1026.

A method for predicting canopy wetness and humidity from remotely-acquired meteorological and radiation data is described. This method employs a surface energy balance model to scale from the above-canopy macroclimate to in-canopy microclimate conditions. Above-canopy temperature, vapor pressure, and wind speed inputs were obtained from objective analyses of hourly measurements from the synoptic weather network, while downwelling long- and shortwave radiation forcings were estimated from standard satellite observations. Precipitation (irrigation + rainfall) was the only input acquired in-field. Model predictions compared well with measurements of nighttime dew accumulation and relative humidity made in irrigated potato crops grown in central Wisconsin. Maximum dew amount measured in full canopies over four nights was reproduced to within 0.05 to $0.1 \mathrm{~mm}$. The practical utility of this method to disease management was assessed by processing modeled and measured canopy microclimate data from two weather stations over three growing seasons through the BLITECAST disease forecasting system. Given the uncertainties inherent in the measurement of humidity, the model reasonably reproduced disease severity values generated from in-situ measurements in all but one case, where the canopy had suffered partial defoliation. Because the model simulates the microclimate within a healthy, uniform canopy, it may in many cases produce more reliable regional forecasts for plant disease than would a single set of in-situ measurements.
\end{abstract}

Additional keywords: disease prediction, integrated pest management, leaf wetness, weather model

With many plant fungal diseases, germination and infection occur only in the presence of free water $(32,38)$. Duration of leaf wetness has therefore become an important input to disease prediction models developed for a wide variety of crops $(8,15,20,23,24,30,36)$. In practice, however, it can be difficult and costly to accurately monitor leaf wetness in the field, so a threshold in relative humidity ( $\mathrm{RH}$; e.g., $\mathrm{RH}>90 \%$ ) is often used as a proxy $(20,22,24,34,39,40)$. In this case, proper positioning of the humidity sensor used to collect data for model development and implementation can be critical to successful prediction of disease outbreak.

Most physically relevant to the infection process itself is the microclimate in which the pathogens reside; i.e., inside the

Corresponding author: M. C. Anderson

E-mail: mcanders@ facstaff.wisc.edu

Accepted for publication 1 May 2001.

Publication no. D-2001-0625-03R

(C) 2001 The American Phytopathological Society boundary layer of still air surrounding the leaf surface. Conditions at the leaf surface, however, are not easily monitored; indeed, the act of measurement itself can alter the state of the boundary layer. Therefore, empirical disease models are generally developed with measurements made in the airspace within the plant canopy. When a model is used in forecasting mode, optimal inputs presumably would be collected in a comparable position within the canopy, but logistical considerations (maintenance, interference with machinery, etc.) often result in placement of weather sensors above the canopy, or even outside the field. The effects of substituting remote measurements may not be important when the canopy is sparse but will increase as the crop develops, sometimes necessitating adjustment of model parameters and thresholds (17). For out-of-field substitutions, the quality of prediction has been found to degrade significantly as the distance from field to weather station increases (14).

While direct substitution of remote observations for in-canopy observations is not a general solution for operational plant disease prediction, models can be employed to link macro- and microclimatic conditions through energy-balance $(29,31,42)$ or empirically-derived relationships (16). Identification of reliable schemes for using remote data sources in disease prediction will reduce pressure on individual growers to install and operate expensive in-field weather stations, and may extend forecasting capabilities to developing nations where dense agricultural weather networks are prohibitively expensive.

In this study, we used a physical model of energy exchange in the soil-plantatmosphere system to scale remotelyacquired measurements of relevant meteorological and radiative quantities into the canopy and leaf boundary layer to predict in-canopy moisture conditions. The use of empirical relationships in the energy balance model was intentionally minimized to facilitate portability between different crops and climatic regions. Still, the model was kept simple enough so that required input parameters and variables can be generally ascertained. We tested the model with meteorological inputs interpolated from national weather network data and radiative inputs derived from operational satellite imagery. In-canopy dew accumulation and humidity predictions were compared with in-situ measurements acquired in irrigated potato crops grown in central Wisconsin.

\section{MATERIALS AND METHODS}

Microclimate model. The model of atmosphere-land exchanges (ALEX; 2) used in this study was developed for practical application in agricultural and mesoscale forecasting products $(1,3,9,21,27)$. ALEX is a simplified form of a comprehensive mechanistic model of canopy-environment interactions (Cupid; 26,28), requiring fewer input specifications and less computing time while producing similar predictions of canopy state and flux variables.

The ALEX model describes the transport of heat, water vapor, carbon, and momentum within the soil-plant-atmosphere system using physical principles of energy balance and turbulent exchange. The conceptual structure of the model is depicted in Figure 1. Temperature $(T)$ and vapor pressure $(e)$ conditions in the airspace 
within the canopy (subscript "ac") are coupled to conditions at the leaf ("c") and soil ("s") surfaces and to conditions above the canopy ("a"). The relative coupling to each of these surfaces depends inversely on the relative magnitudes of the resistance to transport through the bulk leaf boundary layer $\left(R_{b}\right)$, the boundary layer above the soil $\left(R_{s}\right)$, and the surface layer above the canopy $\left(R_{a}\right)$. These resistances depend primarily on wind speed, but also on vegetation cover and atmospheric stability. In practice, above-canopy conditions are provided by a regional weather network, while deep-soil temperature and moisture contents are fixed at reasonable values. The model then diagnoses in-canopy, leaf surface, and soil-profile conditions.

Of particular importance to disease forecasting is the ability to model leaf wetness duration accurately. In ALEX, free water accumulates on leaf surfaces through the interception of rainfall or irrigation waters, or through condensation when the vegetation temperature falls below the dewpoint inside the canopy. In either case, the thickness of the film of standing water is limited in the model to $\leq 0.15 \mathrm{~mm}$ per unit leaf area, based on field measurements in potato made by Wilson et al. (41). Any water accumulated in excess of this threshold is assumed to drip to the soil surface. The rate of evaporation of free water from the leaf surfaces is regulated by the modeled divergence of net radiation within the canopy (2).

This model is distinct from others that have been used to predict leaf wetness $(4,16,29)$ in that it considers the role of soil moisture content in modulating dew deposition rates. In numerical experiments with Cupid, a wet soil was found to extend the period of leaf wetness by 2 $h$ with respect to dry soil simulations (41). In ALEX, dew deposition occurs when $e_{a c}$ exceeds $e^{*}\left(T_{c}\right)$, the saturated vapor pressure at the temperature of the leaf surface. Given the series resistance network described in Figure 1, the vapor pressure in the in-canopy airspace $\left(e_{a c}\right)$ is influenced not only by the atmospheric vapor pressure, but also by evaporative fluxes from the leaf and soil surfaces and by canopy transpiration rates. The timedependent soil water $(\theta)$ profile is computed numerically using Richard's Equation, taking into account root uptake, drainage, and soil evaporation fluxes (2).

Canopy closure is another important factor in predicting in-canopy moisture conditions. As the vegetative cover approaches $100 \%$, the airspace within the canopy becomes less tightly coupled to atmospheric fluctuations. McNaughton and Jarvis (25) show that negative feedback systems develop within a canopy system that tends to stabilize transpiration fluxes, while isolated leaves will respond more rapidly to changes in the atmosphere. If the modifying effect of the canopy is ignored, mod- eled values of in-canopy RH may exhibit more volatile behavior than is observed in nature.

In ALEX, atmospheric decoupling is captured by varying the relative magnitudes of the resistance factors $R_{b}$ and $R_{a}$ (Fig. 1) through the growing season. The bulk leaf boundary layer resistance, $R_{b}$, is inversely proportional to the canopy leaf area index (LAI), assuming fluxes of heat and water vapor from individual leaves add in parallel to form the bulk canopy flux. As $R_{b}$ decreases relative to $R_{a}, T_{a c}$ and $e_{a c}$ become more tightly coupled to conditions at the leaf surface. However, the aerodynamic resistance, $R_{a}$, will also decrease somewhat as the canopy grows because the plants increase local surface roughness, thereby amplifying turbulent eddies above the field. At any given time, the balance between these two transport processes (humidification of the in-canopy airspace through transpiration, and purgation with drier air from above the canopy through turbulent exchange) will depend on the physiology and architecture of the crop in question.

Because the relationships between macro- and in-canopy microclimate change as the crop develops, empirical models developed from data collected during one phase of crop growth may not work well in other phases. In ALEX, effects on system fluxes due to vegetation cover, surface roughness, plant height, and leaf size are modeled explicitly so that the model can be applied to both sparse and dense canopies. In the extended simulations of canopy microclimate presented below, these parameters have been tied to a crop growth model driven by thermal time accumulation. The predictive power of the model will be limited by the accuracy of these estimates.

Remote data sources. Anderson et al. (2) list all input data and parameter specifications required by the ALEX energy balance model. Time-dependent inputs include hourly measurements of abovecanopy temperature, vapor pressure, wind speed, precipitation, and downwelling short- and longwave radiation, and weekly or biweekly estimates of canopy height and cover. These inputs have potential for remote acquisition. In addition, the soil submodel requires information regarding the soil's optical, thermal, and hydraulic properties. These parameters can be estimated from in-field measurements of soil texture and will be relatively stable over time.

In this study, hourly surface meteorological inputs have been derived from synoptic observations acquired by the regional Automated Surface Observing System (ASOS) and Automated Weather Observing System (AWOS) networks, operated by the National Weather Service, Federal Aviation Administration, and Wisconsin Department of Transportation-Bureau of Aviation. These stations, typically situated at airports, monitor air temperature and vapor pressure at $1.5 \mathrm{~m}$ above the surface and wind speed at $10 \mathrm{~m}$. Figure 2 shows the distribution of ASOS/AWOS stations currently commissioned in the state of Wisconsin. To estimate local conditions at arbitrary locations within the state, these station data were spatially interpolated onto regular grids using the objective analysis technique of successive corrections (7) with a Cressman-type spatial weighting function (6). The analysis grid cells were separated by $0.4^{\circ}(\sim 40 \mathrm{~km})$.

Agreement between local conditions and weather data extracted from the analysis grids will vary with distance from the closest ASOS/AWOS station and with climatic peculiarities of the site in question (e.g., local topography, distance to windbreaks, etc.). Figure 3 demonstrates the level of
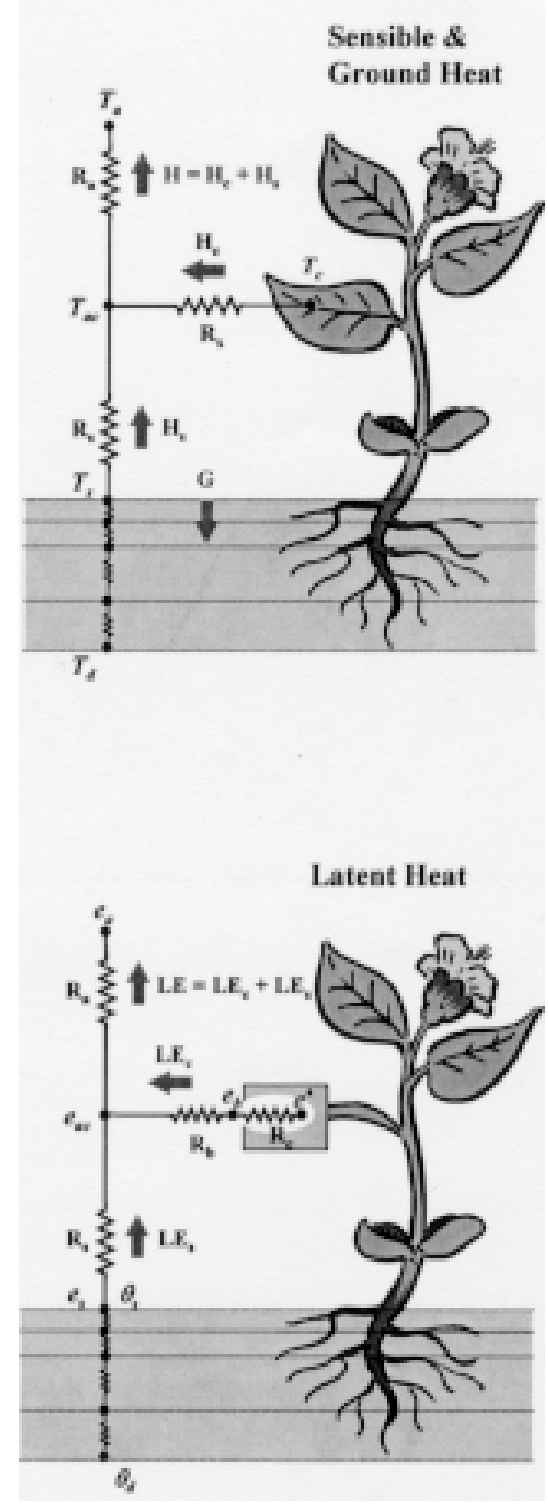

Fig. 1. Conceptual diagram of the ALEX crop microclimate model. Fluxes of latent (LE), sensible $(\mathrm{H})$, and conducted soil heat $(\mathrm{G})$ are driven by gradients in vapor pressure $(e)$ and temperature $(T)$, and regulated by appropriate measures of resistance to transport $(\mathrm{R})$. 
accuracy typical for agricultural regions in the state of Wisconsin. Analyzed temperature, vapor pressure, and wind speed data are compared with measurements taken in 1998 (May-August) at an automated weather station at the Hancock Agricultural Research Station, in the heart of the potatogrowing region in central Wisconsin (Fig. 2). This station is $35 \mathrm{~km}$ from the closest ASOS/AWOS station used in the analysis. Atmospheric temperature and vapor pressure in this region are relatively conservative over large spatial scales, and are therefore well reproduced in the analysis. Wind speed, on the other hand, can be strongly influenced by local surface features, increasing the scatter in comparison with local measurements.

Radiative forcing inputs are critical to model evaluations of condensation and evaporation processes; nighttime dew accumulation is particularly sensitive to thermal emission from the sky and clouds. The radiation products used in this study employ simple methods for reconstructing fields of downwelling of shortwave (solar) and longwave (sky + cloud) fluxes from hourly visible and thermal images acquired with the GOES-8 Geostationary Operational Environmental Satellite.

The shortwave reconstruction method is a simple model of conservation of radiant energy within the earth-atmosphere column, taking into account Rayleigh scattering, water vapor, ozone absorption, and reflection at the earth and cloud surfaces $(10,12,13)$. The resolution of the GOES-8 visible imager channel used to create these shortwave estimates is $1 \mathrm{~km}$ at nadir, and about $1.6 \mathrm{~km}$ at the latitude of Wisconsin. Currently, the shortwave product is being generated at a resolution of $20 \mathrm{~km}$ (Wisconsin latitude), but may be available at higher resolutions in the future. Comparisons with ground-based pyranometer measurements indicate an accuracy of $\pm 10 \%$ for daily shortwave radiation estimates (10).

The longwave product relies on estimates of cloud height and effective areal coverage retrieved from GOES-8 sounder observations (19). These cloud evaluations are used to adjust an empirical clear sky estimate of longwave radiation, enhancing the downwelling component to incorporate thermal emission from the cloud base (11). The GOES cloud products currently have a resolution of $30 \mathrm{~km}$, defining the potential resolution of the longwave grid. With this simple parameterization, daily model estimates match ground-based pyrgeometer measurements to within $\pm 10 \%$ (11).

Validation data. To test the accuracy of this modeling system in predicting incanopy moisture conditions, field measurements of dew accumulation and humidity in potato canopies have been compiled for comparison with model output.

In 1992 and 1994, Wilson et al. (41) measured rates of dew deposition in irri- gated potato crops grown on Plainfield loamy sand near the Hancock Agricultural Research Station. Dew accumulation was estimated over four nights at approximately hourly intervals by bagging wet leaves, measuring wet and dry weights, and extrapolating to a canopy level using the measured LAI, which ranged from 4 to 5. Concomitantly, continuous measurements of air temperature, vapor pressure, wind speed, precipitation, solar, and net radiation were acquired above the canopy at a height of $2 \mathrm{~m}$.

Over the past several years, W. R. Stevenson and R. V. James (personal communication) have recorded hourly humidity data with in-canopy weather stations maintained at the Hancock research station and in a commercial potato field near the Village of Plover (Fig. 2) for purposes of studying blight forecasting. During the 1998, 1999, and 2000 growing seasons, trial plots around the Plover and Hancock weather stations were planted in late April with Goldrush (early) and Russet Burbank (late) cultivars, respectively. Fifty percent emergence occurred at both sites by midMay (Table 1). Both plots were irrigated regularly with a center pivot system, and were fertilized and treated with fungicide sprays to control blight. Vines were killed in early September prior to harvesting.

The weather stations at these sites were equipped with a CS500 relative humidity and temperature probe (Campbell Scientific Inc., Logan, UT) encased in a 6-plate radiation shield and positioned approximately $30 \mathrm{~cm}$ above the hilltop. The manufacturer specifications for the CS500 RH sensor quote an accuracy of $\pm 3 \%$ when $\mathrm{RH}$ is between 10 and $90 \%$, and $\pm 6 \%$ for $\mathrm{RH}$ $>90 \%$, with a typical long-term stability of better than $1 \%$ RH per year. The statistical signature of these errors can vary with sensor, particularly at high humidity levels

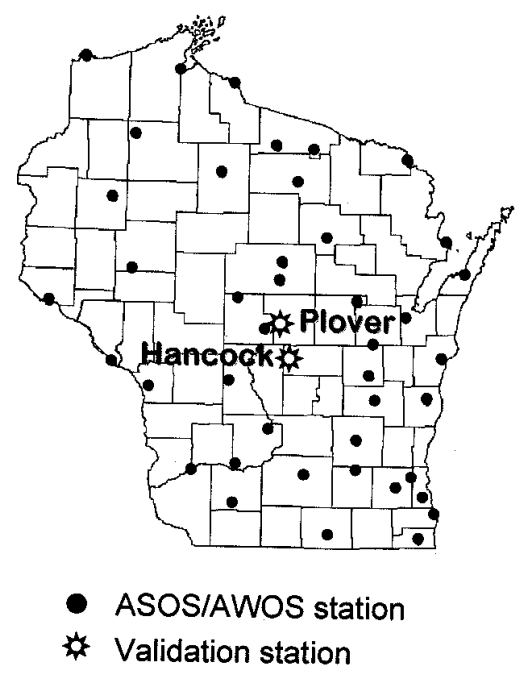

Fig. 2. Distribution of ASOS/AWOS stations across the state of Wisconsin, circa 2000. Also shown are the locations of the Hancock and Plover weather stations, used for validation. where accuracy degrades. Humidity sensors at both Plover and Hancock were sent back to the manufacturer for recalibration prior to the 1998 season, but were not recalibrated in 1999. New capacitance chips

$1.5 \mathrm{~m}$ Temperature (C)

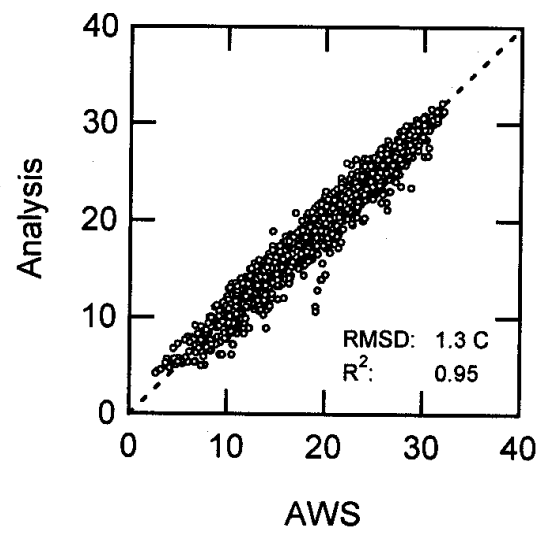

1.5 m Vapor Pressure (kPa)

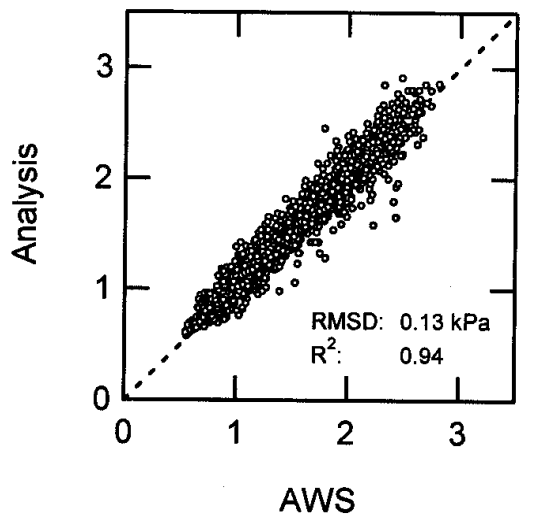

$10 \mathrm{~m}$ Wind speed $(\mathrm{m} / \mathrm{s})$

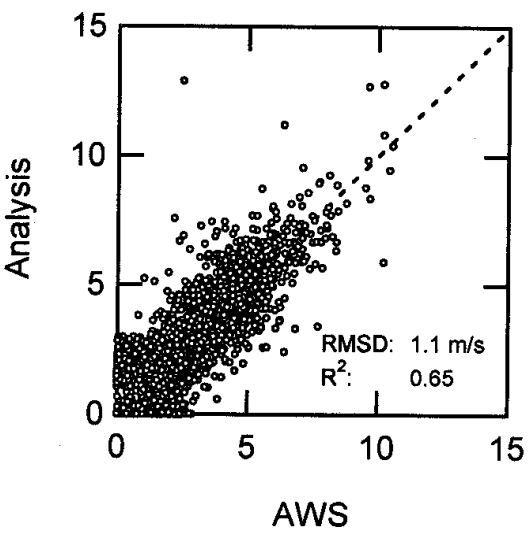

Fig. 3. Comparison of temperature, vapor pressure, and windspeed data extracted from surface analyses of ASOS/AWOS data with measurements taken with an automated weather station (AWS) at Hancock in 1998. Both analyses and measurements represent hourly averages at specified heights above the ground. The root-mean-square deviation (RMSD) and coefficient of determination $\left(\mathrm{R}^{2}\right)$ for each comparison is indicated. 
were installed in 2000. Precipitation (rainfall + irrigation) was monitored at canopy level with a tipping bucket rain gauge.

Model simulations. Simulations with the ALEX energy-balance model were generated for comparison with these dew and humidity observation datasets.

The four nights of dew observations were simulated with inputs assembled and reported by Wilson et al. (41), using meteorological data acquired at $2 \mathrm{~m}$ above the canopy as upper boundary conditions, and direct measurements of LAI, canopy height, and leaf size. Soil properties were assigned to be consistent with existing measurements on Plainfield sand.

The continuous in-canopy humidity measurements of Stevenson and James were simulated using remote estimates of above-canopy temperature, vapor pressure, wind speed, and downwelling radiation. In this experiment, the only time-dependent input data acquired in-field were hourly measurements of precipitation and irrigation amounts. Canopy growth parameters and surface roughness were tied to an empirically-derived relationship between physiological day (P-Day) thermal time units accumulated from the date of $50 \%$ emergence (33) and measurements of percent vegetation cover $\left(f_{c}\right)$ made in irrigated potato crops grown in Wisconsin (5). Canopy height and leaf size were then constrained to grow in proportion to $f_{c}$; height between limits of 0.1 to $0.5 \mathrm{~m}$, and leaf size from 2 to $10 \mathrm{~cm}$ (reflecting the dimension of the compound potato leaf). Surface roughness was approximated as a fixed fraction of the canopy height (35); this fraction was adjusted to give optimal agreement over the six site-years of observations.

\section{RESULTS}

Dew amount and duration prediction. Figure 4 compares model predictions of dew accumulation with measurements made in potato by Wilson et al. (41). The time behavior in evening condensation rate is well reproduced, suggesting that the model-derived bulk vegetation temperature is reasonably representative. The peak dew amount was underestimated by 0.05 to 0.1 $\mathrm{mm}$ in each case, but this discrepancy may also reflect observational errors originating in assumptions required to scale the indi- vidual leaf measurements up to a canopy total. Note that the suppression of dew on the night of 21 to 22 August 1992 has been captured by the model. On this night, the soil surface was particularly dry, and the nighttime relative humidity did not exceed $90 \%$.

In-canopy humidity prediction. Time traces of in-canopy RH measured at the Hancock and Plover experimental sites in 1998 are compared with modeled humidities in Figure 5A. The level of accuracy demonstrated here is similar to that obtained in simulations of the 1999 and 2000 growing seasons for time periods when the modeled canopy was close to full cover. Greater disparity is noted earlier in the season, when the cover was sparse. Agreement during this early phase of crop growth would likely be improved with onsite measurements of LAI.

Figure 5B demonstrates the utility of the surface energy balance model in scaling from the macro- to microclimate. Here, modeled in-canopy RH is compared with the above-canopy measurements (at $1.5 \mathrm{~m}$ ) that served as the upper boundary conditions for the model simulations, extracted from the ASOS/AWOS analyses at the locations of the experimental plots. The additional humidification of the airspace within the closed canopy is clearly evident here. During this phase of cover development, disease forecasts based on in-situ RH measurements could be strongly biased by vertical (and horizontal; see below) variations in sensor placement.

The durations of modeled high-humidity events $(\mathrm{RH}>90 \%)$ are plotted in Figure 6 along with durations measured at both experiment sites during the 1998 to 2000 growing seasons. As is the practice in some disease forecasting algorithms (37), a twohour gap with RH $<90 \%$ is tolerated within events to reduce sensitivity to shorttimescale sensor fluctuations; gaps of longer duration serve to terminate the event. Because high humidity is generally a nighttime phenomenon, event "start dates" have been defined from noon to

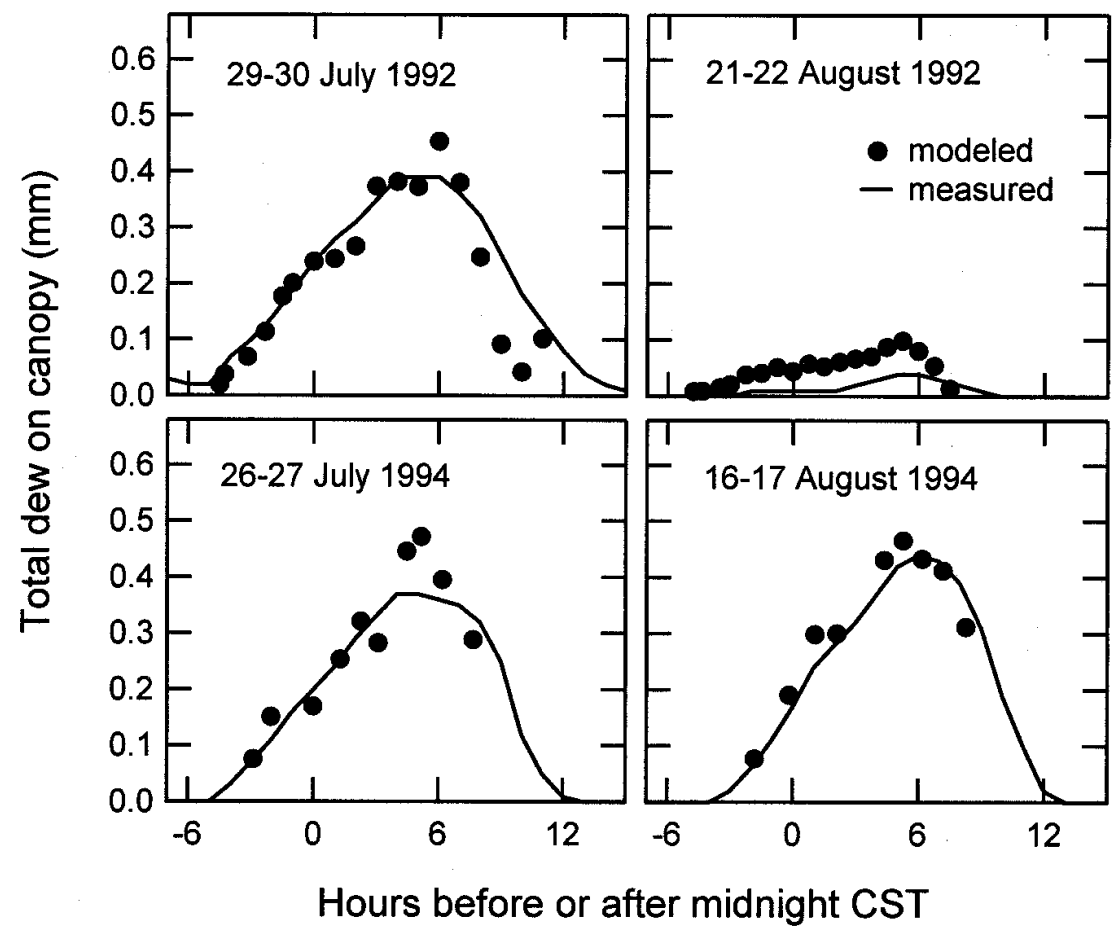

Fig. 4. Comparison of measurements of overnight dew accumulation made in potato canopies by Wilson et al. (41) with condensation predicted with the ALEX model.

Table 1. Dates of 50\% potato emergence at the Hancock and Plover experimental sites, expressed in day of year. Also dates of accumulation of 18 SVs based on modeled and measured $\mathrm{RH}$, with error ranges associated with $\pm 1 \%$ and $\pm 3 \%$ sensor biases

\begin{tabular}{|c|c|c|c|c|c|c|c|c|c|}
\hline \multirow[b]{3}{*}{ Site (bias) } & \multicolumn{3}{|c|}{1998} & \multicolumn{3}{|c|}{1999} & \multicolumn{3}{|c|}{2000} \\
\hline & \multirow[b]{2}{*}{$50 \%$ emergence } & \multicolumn{2}{|c|}{$18 \mathrm{SVs}$} & \multirow[b]{2}{*}{$50 \%$ emergence } & \multicolumn{2}{|c|}{$18 \mathrm{SVs}$} & \multirow[b]{2}{*}{$50 \%$ emergence } & \multicolumn{2}{|c|}{$18 \mathrm{SVs}$} \\
\hline & & Observed & Modeled & & Observed & Modeled & & Observed & Modeled \\
\hline $\begin{array}{l}\text { Hancock: } \\
(+1 \%,-1 \%) \\
(+3 \%,-3 \%)\end{array}$ & 133 & $\begin{array}{c}161 \\
(161,161) \\
(161,163)\end{array}$ & 159 & 140 & $\begin{array}{c}155 \\
(151,155) \\
(151,155)\end{array}$ & 155 & 139 & $\begin{array}{c}155 \\
(152,155) \\
(152,165)\end{array}$ & 152 \\
\hline $\begin{array}{l}\text { Plover: } \\
(+1 \%,-1 \%) \\
(+3 \%,-3 \%)\end{array}$ & 134 & $\begin{array}{c}161 \\
(161,161) \\
(160,167)\end{array}$ & 161 & 140 & $\begin{array}{c}161 \\
(155,162) \\
(151,173)\end{array}$ & 156 & 138 & $\begin{array}{c}152 \\
(152,152) \\
(152,152)\end{array}$ & 152 \\
\hline
\end{tabular}


noon: events starting before noon on a given day were assigned to the previous day. Note that several multi-day events $(>24 \mathrm{~h})$ were recorded during this 3-year period.

In general, observed high-humidity events are well reproduced by the model. Given the threshold basis of this metric, however, the duration of a unique event can be very sensitive to small biases and fluctuations in RH. Note, for example, the high-humidity events starting on days 168 and 183 during the 1998 season at Hancock (Figs. 5A and 6). While the modeled and measured RH time traces are quite similar during these time frames (Fig. 5A), the modeled trace fell just below $90 \%$ for over $2 \mathrm{~h}$, breaking the observed 30 -h event into two shorter modeled events (Fig. 6). At Plover, the model and measurements yield similar event durations on these days. Other highly discrepant events that would have been merged or broken given only a $\pm 3 \%$ bias in the observations are indicated in Figure 6. In other cases, extended events in the model and measurement datasets started around noon and were assigned to different start dates (see, for example, events at Plover and Hancock starting on day 198 in 1999; Fig. 6). The model output for Hancock in 1998 shows an early-season bias toward higher humidities that likely reflects differences between local canopy cover in the vicinity of the RH sensor and predictions from the P-day crop development model.
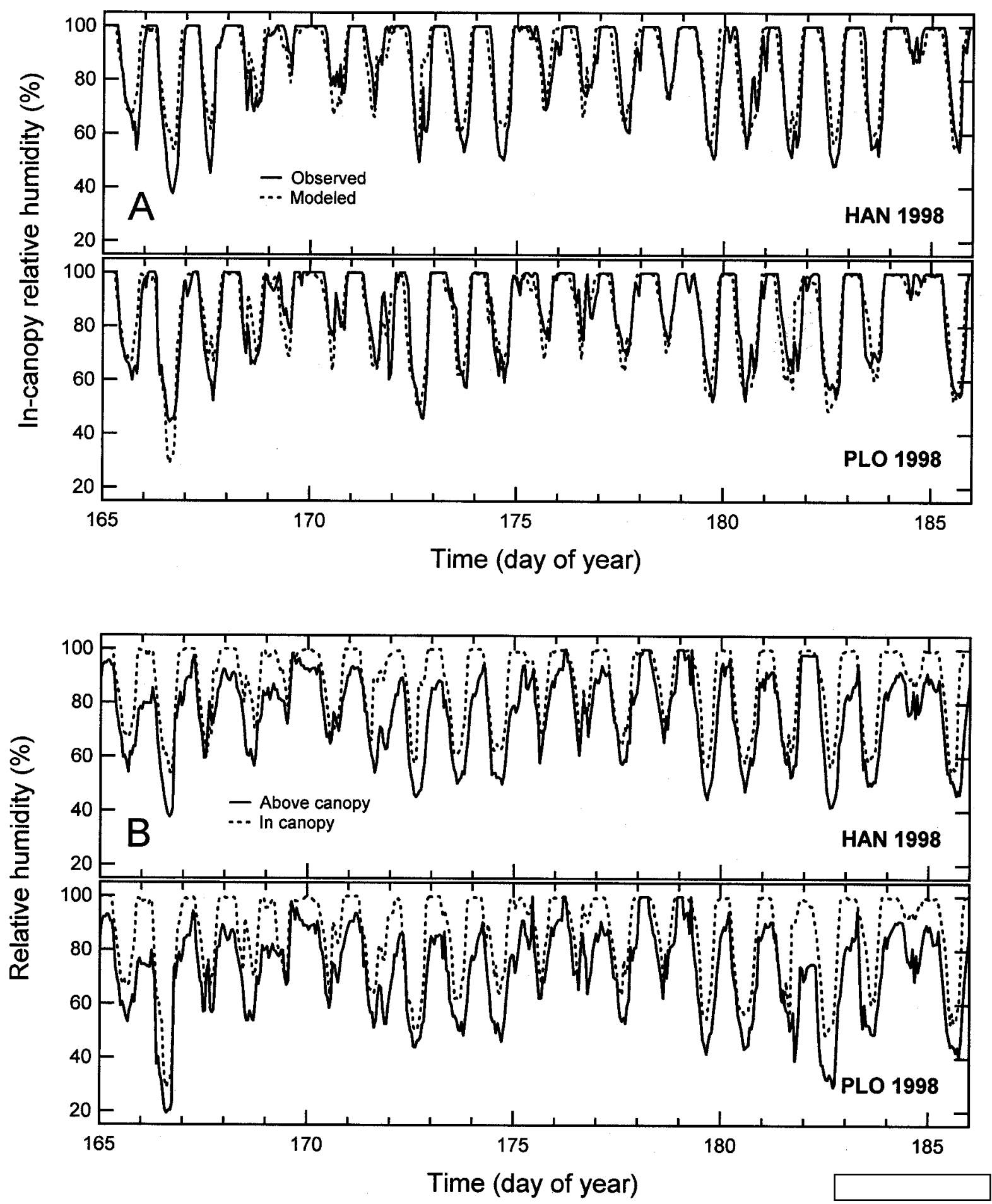

Fig. 5. Time-traces of relative humidity (RH) from Hancock and Plover in 1998: A, comparison of modeled (dashed line) and measured (solid line) incanopy RH; B, comparison of above-canopy RH extracted from ASOS/AWOS analyses (solid) with modeled in-canopy RH (dashed). 
Table 2. Performance of energy-balance model in reproducing high-humidity events observed in canopy at Hancock and Plover during the 1998-2000 growing seasons

\begin{tabular}{ccccc}
\hline & Number of occurrences & \multicolumn{3}{c}{ Model accuracy } \\
\cline { 3 - 5 } Event duration & in observations & \% correct & \% within 1 h & \% within 2 h \\
\hline$<10 \mathrm{~h}$ & 159 & 55 & 70 & 82 \\
$10-15 \mathrm{~h}$ & 200 & 92 & 98 & 98 \\
$16-21 \mathrm{~h}$ & 54 & 65 & 74 & 81 \\
$22-27 \mathrm{~h}$ & 4 & 25 & 75 & 100 \\
$>27 \mathrm{~h}$ & 33 & 76 & 76 & 76 \\
Total & 450 & 74 & 83 & 89 \\
\hline
\end{tabular}

The accuracy with which the model identified high-humidity events observed incanopy is assessed in Table 2. Event duration categories used in this assessment $(<10$ h, 10 to $15 \mathrm{~h}, 16$ to $21 \mathrm{~h}, 22$ to $27 \mathrm{~h}$, and $>27$ h) are generalized from intervals (generally $3 \mathrm{~h}$ ) used in the BLITECAST algorithm for forecasting late blight in potato (22). Within these categories, the model exactly predicted durations for $74 \%$ of 450 site-days of observations at Hancock and Plover, was within 1 $\mathrm{h}$ for $83 \%$ of these site-days, and within $2 \mathrm{~h}$ for $89 \%$ of the site-days.

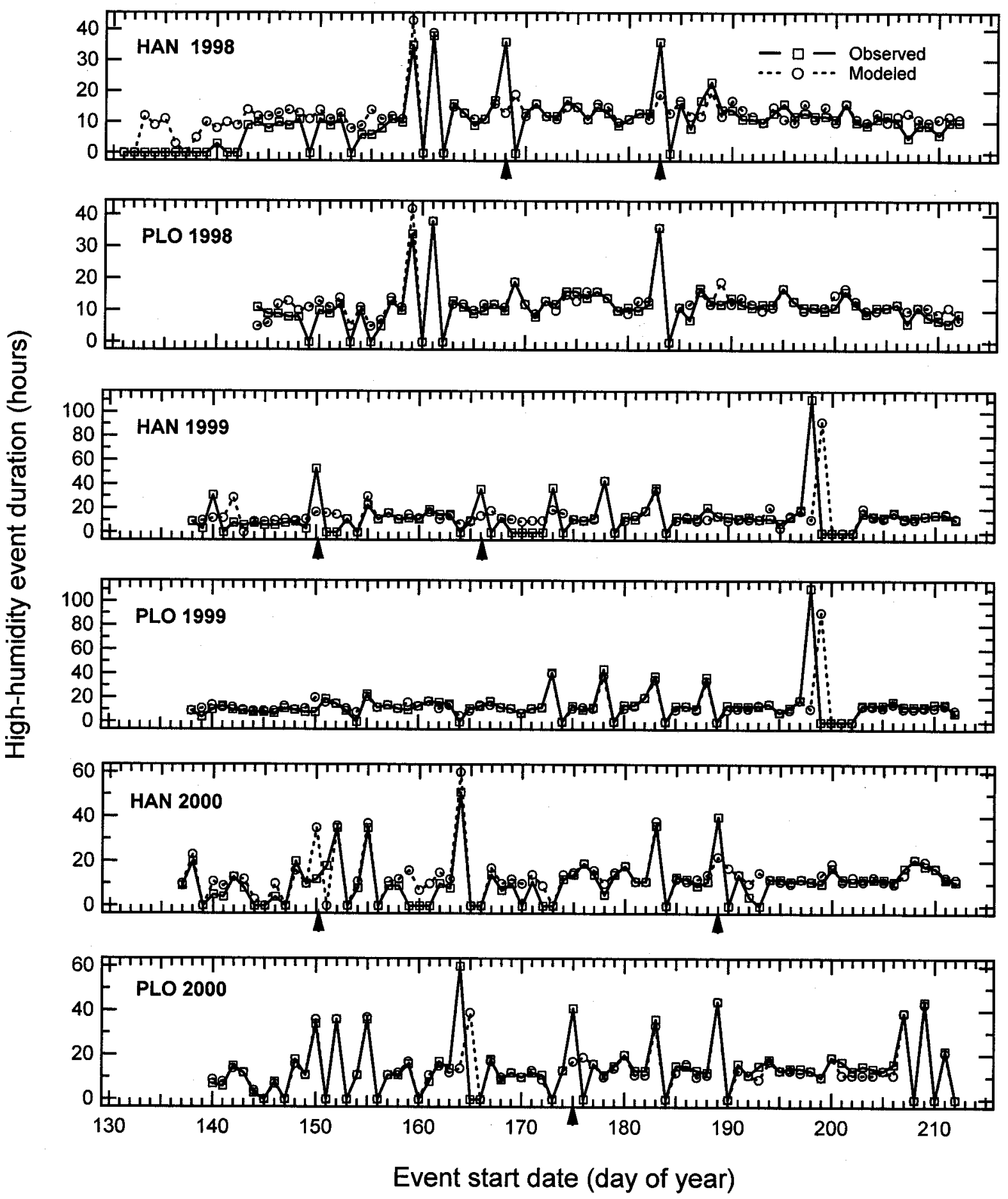

Fig. 6. Modeled (dashed line) and measured (solid line) high relative humidity event durations at Hancock and Plover during the $1998-2000$ growing seasons. Arrows indicate events that would be merged or broken given a $\pm 3 \%$ bias in the observations. 
Disease severity prediction. The practical utility of this moisture prediction scheme in scheduling fungicide applications can be evaluated by processing modeled and measured canopy microclimate data through a standard forecasting system. bodies an empirical relationship between in-canopy temperature and humidity patterns and observations of the development of late blight in potato. Given a weather data stream, the algorithm identifies extended periods $(>10 \mathrm{~h}$, with tolerated gaps of $\leq 2 \mathrm{~h}$ ) of high relative humidity $(\geq 90 \%)$ and determines the average temperature during each high-RH event. An incremental severity value (SV) is computed from the event duration and average temperature; SV accumulations during the growing season drive the fungicide spray recommendations. When the inoculum is present, late blight is anticipated 7 to 14 days after 18 severity values have accumulated from the date of emergence.

Severity value accumulations based on
The BLITECAST algorithm (22) em-

the modeled and measured temperature and humidity data are compared between emergence and 1 August, when most late blight management decisions are made (Fig. 7). As with threshold-based metrics, cumulative metrics are sensitive to small biases in input; in this case, the effects of a bias will amplify with time. The hatched area in Figure 7 indicates possible accumulation rates given a $\pm 3 \%$ constant bias in the in-canopy humidity sensor, a conservative estimate of the functional reliability of the CS500 RH sensor near the $90 \%$ threshold. Additional biases may accrue if the sensor is sited in an unrepresentative location within the canopy (see below).

In general, the cumulative SV curves derived from the remote humidity estimates lie within this error range. Table 1 lists dates of accumulation of $18 \mathrm{SVs}$ using both modeled and in-situ weather data. This is the most important milestone in the BLITECAST forecasting algorithm; i.e., fungicide sprays for late blight are recommended after this threshold has been

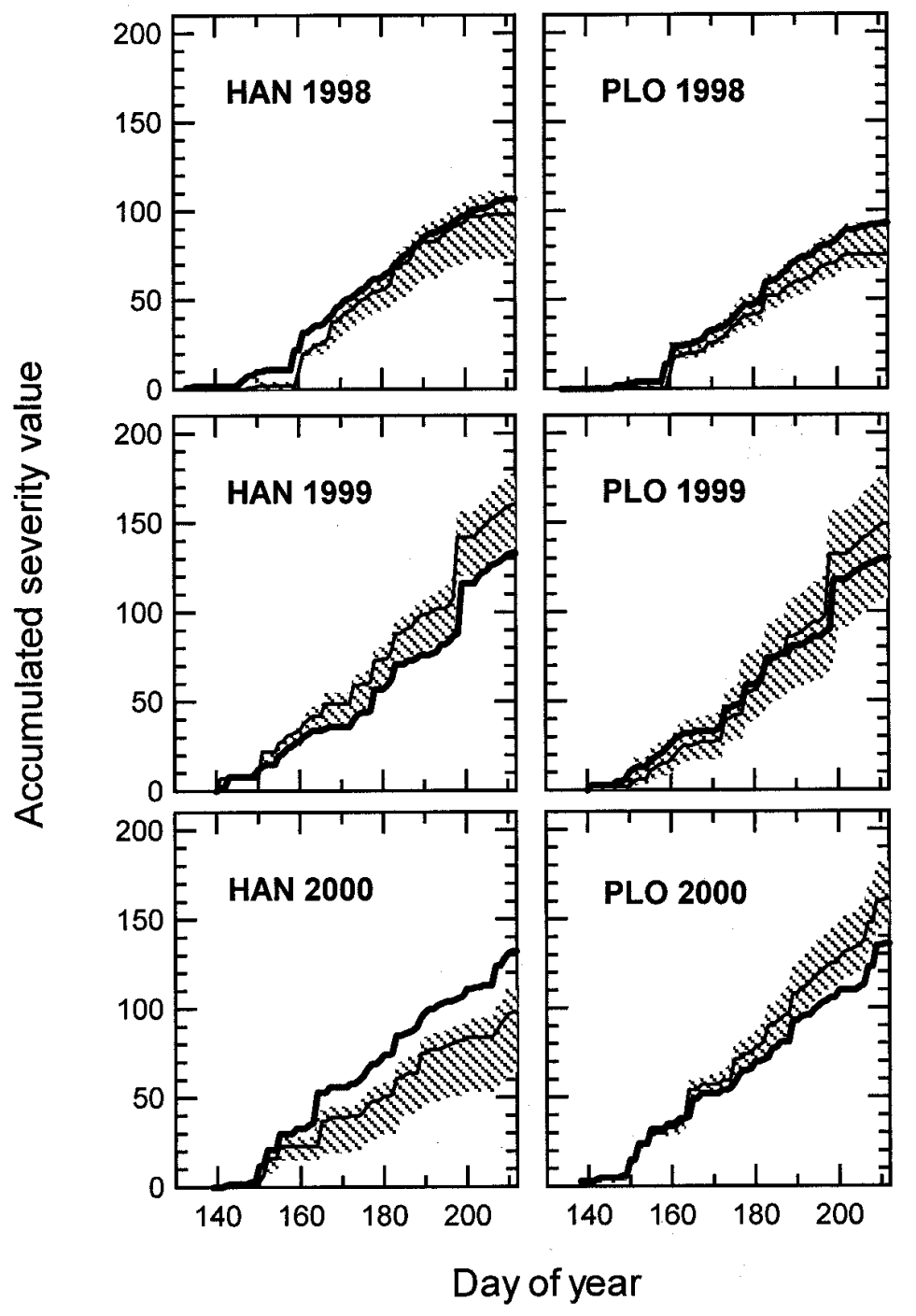

Fig. 7. Modeled (thick line) and measured (thin line) severity value accumulations for the 1998-2000 growing seasons at the Hancock and Plover validation sites. The hatched area indicates an observational error range assuming $\mathrm{a} \pm 3 \%$ constant bias in the relative humidity sensor. reached. Also quoted is a range of dates associated with $\mathrm{a} \pm 1 \%$ and $\pm 3 \%$ bias error in the RH sensor. The modeled $18 \mathrm{SV}$ milestone was, in most cases, attained within the expected date range assuming a $\pm 1 \%$ sensor bias. The exception occurred at Hancock in 1998, where the modeled milestone was reached 2 days early. Again, the $18 \mathrm{SV}$ milestone provides a 1 - to 2 week warning of impending infection, so a 2-day error may be tolerable. Indeed, forecasts based on the in-field measurements made at Plover in 1999 would have resulted in a week spread in first spray recommendation given only a $\pm 1 \%$ bias in the sensor used.

Severity values accumulated at comparable rates at Hancock and Plover during the 1998 and 1999 growing seasons. In 2000, however, the Hancock accumulation curve based on in-canopy measurements consistently lagged behind Plover. Despite fungicide applications, the field hosting the in-canopy weather station at the Hancock Agricultural Research Station in 2000 experienced significant defoliation early in the season, in comparison with the commercial field near Plover. The idealized vegetation growth curve therefore overestimated local leaf area at Hancock, resulting in higher in-canopy humidity predictions and modeled severity accumulations that were more comparable to those acquired at Plover.

\section{DISCUSSION}

Model performance. The experiments reported here demonstrate a technique for predicting in-canopy microclimate variables using remote data sources, including standard synoptic-scale weather observations and satellite imagery. In these cases, in-canopy $\mathrm{RH}$ and dew deposition were predicted with reasonable accuracy in comparison with observations, particularly during the nighttime hours when humidity levels tend to be highest. Disease forecasts from the BLITECAST algorithm based on modeled and measured in-canopy humidity and temperature data produced similar recommendations for the onset of fungicide applications, given a conservative estimate of observational errors due to sensor siting and calibration maintenance.

The infrastructure required to implement this modeling approach on an operational basis has only recently become generally available. The wide-scale deployment of automated weather stations during the 1990s significantly improved the coverage and cost-efficiency of the synoptic weather network in the United States. New methods for quantifying cloud cover from standard satellite observations have recently been developed, facilitating specification of critical radiative forcings at high spatial resolution over large areas. Finally, the recent explosion in the power and ubiquity of the Internet has greatly simplified the process of data collection, processing, and 
dissemination to the agricultural community.

The simulations presented here used onsite measurements of precipitation (rainfall + irrigation). All other time-dependent inputs were obtained from remote sources. We are currently investigating the efficacy of using Stage III WSR-88D (NEXRAD) radar-derived data to estimate rainfall. In this application, simulated irrigation events are triggered whenever soil moisture content falls below some specified threshold. While our data at present are limited, it appears that remote substitution of on-site precipitation data does not significantly degrade disease forecasts for irrigated crops. We believe this is possible because extensive, slow-moving storms are well represented in the radar record, while brief, spatially-limited storms missed by the areally-averaged radar data should be compensated for locally by decreased irrigation.

A potential source of error in this remote estimation scheme is introduced in the prediction of canopy development based on thermal time. Vegetation cover strongly influences the in-canopy microclimate, serving to buffer the in-canopy airspace from atmospheric fluctuations. Better characterization of the early growth phase will improve prediction of early high-humidity events, which strongly determine the onset of spraying. Fortunately, vegetation cover fraction is a quantity that can be remotely sensed with reasonable accuracy (18). As high-spatial-resolution satellite imagery become more accessible and affordable, this important model input may also be operationally retrievable from remote sources on the field scale.

Sensor siting bias. It is important to recognize that disease severity values, and therefore resulting spray recommendations, can be significantly affected by the positioning of the RH sensor within the field. Ease of maintenance and potential interference with ground-based spraying equipment, for example, often inspire placement of the weather station near the edge of the field. However, measurements made near the edge may misrepresent the potential for blight outbreak for the field as a whole, particularly if the average fetch (i.e., upwind area) associated with the measurement extends over an unrepresentative land surface (such as bare soil). In this case, the in-canopy sensor will be primarily sampling air advected from outside the field, rather than air that has been humidified by the canopy itself.

Canopy health in the vicinity of the sensor is also critical to regional forecasting, as demonstrated by data collected during the 2000 growing season at Hancock described above. A forecast generated from measurements acquired in a partiallydefoliated canopy will significantly underestimate the potential for blight outbreak in a healthy canopy nearby.
The ALEX surface energy balance model assumes no advection, and thus is representative of measurements made in an extended canopy with ample homogeneous fetch. In effect it simulates an idealized measurement, taken near the center of a large, uniformly irrigated and healthy field. The model forecast might then be considered as a worst-case scenario in terms of varying potential for blight outbreak across a field.

\section{ACKNOWLEDGMENTS}

This research was supported by NASA Grant NAG5-2877 dedicated to the public use of earth and space science data over the Internet. We thank W. R. Stevenson, R. V. James, and T. B. Wilson for providing the field measurements used in this analysis.

\section{LITERATURE CITED}

1. Anderson, M. C., Bland, W. L., Diak, G. R., and Norman, J. M. 1998. An automated cranberry frost forecasting system with real-time ingestion of surface and satellite observations. Pages 5-6 in: 23rd AMS Conference on Ag. and For. Meteorol., AMS, Albuquerque, NM.

2. Anderson, M. C., Norman, J. M., Meyers, T. P., and Diak, G. D. 2000. An analytical model for estimating canopy transpiration and carbon assimilation fluxes based on canopy light-use efficiency. Agric. For. Meteorol. 101:265-289.

3. Bland, W. L., Anderson, M. C., and Diak, G. D. 1998. A potato canopy humidity model driven by GOES and ASOS/AWOS data. Pages 7-8 in: 23rd AMS Conference on Ag. and For. Meteorol., AMS, Albuquerque, NM.

4. Chtioui, Y., Francl, L. J., and Panigrahi, S. 1999. Moisture prediction from simple micrometeorological data. Phytopathology 89:668-672.

5. Connell, T. R., Binning, L. K., and Schmitt, W. G., 1999. A canopy model for potatoes. Am. J. Potato Res. 76:153-159.

6. Cressman, G. 1959. An operational objective analysis system. Mon. Wea. Rev. 87:367-374.

7. Daley, R. 1996. Atmospheric Data Analysis. Cambridge University Press, Cambridge.

8. De Wolf, E. D., and Francl, L. J. 2000. Neural network classification of tan spot and Stagonospora blotch infection periods in a wheat field environment. Phytopathology 90:108-113.

9. Diak, G. R., Anderson, M. C., Bland, W. L., Norman, J. M., Mecikalski, J. M., and Aune, R. M. 1998. Agricultural management decision aids driven by real-time satellite data. Bull. Am. Meteorol. Soc. 79:1345-1355.

10. Diak, G. R., Bland, W. L., and Mecikalski, J. R. 1996. A note on first estimates of surface insolation from GOES-8 visible satellite data. Agric. For. Meteorol. 82:219-226.

11. Diak, G. R., Bland, W. L., Mecikalski, J. R., and Anderson, M. C. 2000. Satellite-based estimates of longwave radiation for agricultural applications. Agric. For. Meteorol. 103:349355.

12. Diak, G. R., and Gautier, C. 1983. Improvements to a simple physical model for estimating insolation from GOES data. J. Clim. Appl. Meteorol. 22:505-508.

13. Gautier, C., Diak, G. R., and Masse, S. 1980. A simple physical model to estimate incident solar radiation at the surface from GOES satellite data. J. Appl. Meteorol. 22:1380-1386.

14. Gillespie, T. J., Srivastava, B., and Pitblado, R. E. 1993. Using operational weather data to schedule fungicide sprays on tomatoes in southern Ontario, Canada. J. Appl. Meteorol. 32:567-573.
15. Gillespie, T. J., and Sutton, J. C. 1979. A predictive scheme for timing fungicide applications to control Alternaria leaf blight in carrots. Can. J. Plant Pathol. 1:95-99.

16. Gleason, M. L., Taylor, S. E., Loughin, T. M., and Koehler, K. J. 1994. Development and validation of an empirical model to estimate the duration of dew periods. Plant Disease 78:1011-1016.

17. Gumestad, N. C., Enz, J. W., Preston, D. A., and Secor, G. A. 1995. Late blight forecasting and dissemination system using an automated weather monitoring system. Phytophthora 150:209-213.

18. Hall, F. G., Townshend, J. R., and Engman, E. T. 1995. Status of remote sensing algorithms for estimation of land surface parameters. Remote Sens. Environ. 51:138-156.

19. Hayden, C. M., and Wade, G. S. 1996. Derived product imagery from GOES-8. J. Appl. Meteorol. 2:153-162.

20. Jones, A. L., Lillevik, S. L., Fisher, P. D., and Stebbins, T. D. 1980. A microcomputer-based instrument to predict primary apple scab infection periods. Plant Dis. 64:69-72.

21. Kongoli, C. E., and Bland, W. L. 2000. Longterm snow depth simulations using a modified atmosphere-land exchange model. Agric. For. Meteorol. 104:273-287.

22. Krause, R. A., Massie, L. B., and Hyre, R. A 1975. BLITECAST, a computerized forecast of potato late blight. Plant Disease Reporter 59:95-98.

23. Latin, R., and Evans, K. J. 1996. Development and delivery of a forecaster for Alternaria leaf blight of muskmelon (Abstr.). Phytopathology 86:S106.

24. Madden, L., Pennypacker, S. P., and MacNab A. A. 1978. FAST: a forecast system for $\mathrm{Al}$ ternaria solani on tomato. Phytopathology 68:1354-1358.

25. McNaughton, K. G., and Jarvis, P. G. 1991 Effects of spatial scale on stomatal control of transpiration. Agric. For. Meteorol. 54:269301.

26. Norman, J. M. 1979. Modeling the complete crop canopy. Pages 249-277 in: Modification of the aerial environment of plants. B. J. Barfield and J. F. Gerber, eds. Amer. Soc. Agric. Eng., St. Joseph, MI.

27. Norman, J. M., and Anderson, M. C. 1998. ALEX - A portable surface flux model for agricultural and environmental simulations Pages 3-4 in: 23rd AMS Conference on Ag. and For. Meteorol., AMS, Albuquerque, NM.

28. Norman, J. M., and Campbell, G. 1983. Application of a plant-environment model to problems in irrigation. Pages 156-188 in: Advances in Irrigation. D. Hillel, ed. Academic Press, New York.

29. Pedro, M. J. Jr., and Gillespie, T. J. 1982. Estimating dew duration. II. Utilizing standard weather station data. Agric. Meteorol 25:297-310.

30. Pitblado, R. 1992. The development and implementation of TOM-CAST. Ont. Minist. Agric. Food Publ.

31. Rao, P. S., Gillespie, T. J., and Schaafsma, A. W. 1998. Estimating wetness duration on maize ears from meteorological observations. Can. J. Soil Sci. 78:149-154.

32. Royle, D. J., and Butler, D. R. 1986. Epidemiological significance of liquid water in crop canopies and its role in disease forecasting Pages 139-154 in: Water, Fungi and Plants. Ayers, P. G., and Boddy, L., eds. Cambridge University Press, Cambridge.

33. Sands, P. J., Hackett, C., and Nix, H. A. 1979. A model of the development and bulking of potatoes (Solanum tuberosum L.). I. Derivation from well-managed field crops. Field Crops Res. 2:309-331.

34. Shane W. W. and Teng P. S. 1984. Cercospora 
beticola infection prediction model. 1983 Sugarbeet Res. Ext. Rep. 14:174-179.

35. Shaw, R. H., and Pereira, A. R. 1982. Aerodynamic roughness of a plant canopy; a numerical experiment. Agric. Meteorol. 26:51-65.

36. Sutton, J. C., James, T. D. W., and Rowell, P. M. 1986. BOT-CAST: A forecasting system to time the initial fungicide spray for managing botrytis leaf blight of onions. Agric. Ecosyst. Environ. 18:123-143.

37. University of Wisconsin-Extension, 1990. PCM-The Integrated Systems Approach to
Potato Crop Management. University of Wisconsin-Madison.

38. Van der Wal, A. F. 1978. Moisture as a factor in epidemiology and forecasting. Pages 253295 in: Water and Plant Diseases. Vol. 5, Water Deficits and Plant Growth. Kozlowski, T. T., ed. Academic Press, New York.

39. Vincelli, P. C., and Lorbeer, J. W. 1988. Comparison of predictive systems for timing the initial fungicide application to control Botrytis leaf blight of onion. Plant. Dis. 72:632635
40. Wilks, D. S., and Shen, K. W. 1991. Threshold relative humidity duration forecasts for plant disease prediction. J. Appl. Meteorol. 30:463-477.

41. Wilson, T. B., Bland, W. L., and Norman, J. M. 1999. Measurement and simulation of dew accumulation and drying in a potato canopy. Agric. For. Meteorol. 92:111-119

42. Zhang, Y., and Gillespie, T. J. 1990. Estimating maximum droplet wetness duration on crops from nearby weather station data. Agric. For. Meteorol. 51:145-158. 